\title{
Eating habits and attitudes of mothers of children with non-organic failure to thrive
}

\author{
Jacinta B McCann, Alan Stein, Christopher G Fairburn, David B Dunger
}

\begin{abstract}
The eating habits and attitudes concerning body shape and weight among 26 mothers of children with non-organic failure to thrive (the index group) were studied using the eating disorder examination. They were compared with equivalent data on 26 individually matched women who participated in a large community survey. The index mothers' views of their child's weight and shape were also studied.

The principal findings were, firstly, that when compared with the comparison group, mothers of children with nonorganic failure to thrive had higher levels of dietary restraint. Secondly, despite their child's low weight, $50 \%$ of the index mothers were restricting their child's intake of 'sweet' foods, and a further $30 \%$ were restricting foods they considered 'fattening' or 'unhealthy'.

These results raise the question of whether maternal eating habits and attitudes have a causal role in the genesis of non-organic failure to thrive. They suggest that careful inquiry about the mothers' eating habits and attitudes is needed when assessing children with non-organic failure to thrive.

(Arch Dis Child 1994; 70: 234-236)
\end{abstract}

Failure to thrive in young children accounts for between $1 \%$ and $5 \%$ of paediatric admissions to hospital. 1 Thirty to forty per cent of such children are given the diagnosis of 'nonorganic failure to thrive', with no sufficient physiological cause being found. ${ }^{2}$

The aetiology of non-organic failure to

Section of Child and Adolescent Psychiatry, Oxford University Department of Psychiatry, Park Hospital for Children, Old Road, Headington, Oxford OX3 7LQ

Jacinta B McCann

Alan Stein

Oxford University Department of

Psychiatry, Warneford Hospital, Oxford Christopher G Fairburn

Department of Paediatrics, John Radcliffe Hospital, Oxford

David B Dunger

Correspondence to: Dr McCann.

Accepted 3 November 1993 years. It has sometimes been viewed as resulting from emotional deprivation, ${ }^{34}$ although this concept has increasingly been called into question. The presence of adverse environmental factors influencing non-organic failure to thrive has also been observed. ${ }^{5}$ Another viewpoint stems from the finding that when children present with non-organic failure to thrive, their nutritional intake appears to be deficient. $^{6}$ Many authors take the view that whatever the primary aetiology, inadequate energy intake is the final common pathway of the growth failure in non-organic failure to thrive. ${ }^{78}$ Some studies have focused on how the nutritional intake of children with nonorganic failure to thrive becomes inadequate, although no systematic research has been undertaken. In a Dutch study, researchers con- sidered whether particular diets (for example, a macrobiotic diet), adversely influence the growth of young children. ${ }^{10}$ In one case series consisting of seven children, parental health beliefs appeared to lead to restriction of children's food intake. ${ }^{11}$

Two case series have reported that the children of mothers with eating disorders (anorexia nervosa or bulimia nervosa) have feeding difficulties or poor weight gain. ${ }^{12}{ }^{13} \mathrm{In}$ one, some mothers with bulimia nervosa admitted to slimming their babies. ${ }^{14}$ In a Danish retrospective study of mothers with anorexia nervosa a significant number recalled that their children had growth and/or feeding difficulties in the first year of life. ${ }^{15}$ These findings raise the question as to whether the presence of eating disorder psychopathology in mothers may be an aetiological factor in the development of non-organic failure to thrive in their children.

The aim of this study was to determine whether disturbed eating habits and attitudes to body shape, weight, and food are more common among mothers of children with nonorganic failure to thrive than among mothers from the general population.

\section{Subjects and methods \\ SUBJECTS}

Twenty six children with non-organic failure to thrive were identified from the patient lists of two Oxfordshire consultant paediatricians (the index group) having been referred by family doctors in the previous three years. The criteria for entry into the study were that the child's weight at referral was at, or below, the third population centile. ${ }^{1617}$ In addition, the study was restricted to singleton children whose birth weight was above $2500 \mathrm{~g}$, with a gestation of greater than 37 weeks.
ASSESSMENT

Subjects were assessed by interview which comprised of two parts. The first consisted of an examination of the mothers' eating habits and attitudes, using the eating disorder examination. This is a validated investigator based interview which assesses the clinical features of eating disorders. ${ }^{18}$ Five subscales may be derived from its ratings, the key ones being eating restraint, shape concern, and weight concern. The eating disorder examination also generates operational Diagnostic and Statistical Manual of Mental Disorders, third edition, revised (DSM-III-R) eating disorder diagnoses. 
For comparison purposes, equivalent data were extracted on an individually matched subgroup of mothers who participated in a large community based study of the prevalence of eating disorder features among women (C G Fairburn et al, unpublished). Each index mother was paired with the mother who matched her most closely on the following criteria: (i) number of children, (ii) social class, (iii) maternal age.

The second part of the interview addressed the following topics: (A) The events leading up to the referral to the paediatrician. (B) Attitudes and feelings of the mother towards the referral and the follow up procedure. (C) The mother's views on her child's weight and shape: for example, they were asked specifically whether they considered their child of normal weight and if not, what they felt the degree of underweight might be.

Mann-Whitney U tests were carried out to compare the index and comparison mothers' eating disorder examination scores. The paired $t$ test was used to compare change between referral and discharge measures of the childrens' weight deficit for height.

\section{Results}

CHARACTERISTICS OF THE SAMPLE

Of the 26 children identified, 10 were boys, 16 were girls and their mean (SD) age was $3 \cdot 8$ $(2 \cdot 0)$ years (range $0 \cdot 9-9 \cdot 6$ ). The mean age of the index mothers was $30 \cdot 1(4 \cdot 0)$ years (range 24.3-38.8), while that of the comparison group was $29 \cdot 7(3 \cdot 5)$ years (range 24.1-38.0). There was no significant difference between the body mass index of the two groups (mean (SD) $23.78(3.30)$ in the index group $v 23.87$ $(4 \cdot 26)$ in the comparison group).

All birth weights were at or above the 10th centile (mean 25th centile, range 10th-75th centile). From birth to the referral, all demonstrated deteriorating growth and had crossed major centile lines. At referral, the mean weight deficit for height was $22.3 \%$ (range $10 \%-32 \%)$. All children were investigated and none were found to have an organic cause for their failure to thrive.

\section{EATING HABITS AND ATTITUDES OF THE MOTHERS}

None of the mothers in either group fulfilled DSM-III-R diagnostic criteria for anorexia nervosa or bulimia nervosa. However, the index group scored significantly higher on the restraint subscale than the comparison group (index mean 1.78 , comparison mean 0.56 , $\mathrm{p}<0.001)$. The restraint subscale assesses attempts to restrict food intake to influence shape or weight. There was no significant difference between the two groups on the other subscales.

\section{MOTHER'S ATTITUDE TO THE PAEDIATRIC} REFERRAL

Sixty nine per cent (18 mothers) reported their predominant feelings were those of worry and concern; $31 \%$ (eight mothers) were relieved that their child's difficulties with poor weight gain were being acknowledged. The time interval between the child's poor weight gain being first noted by the primary health care team and subsequent referral ranged from one month to three years. The mothers who had to wait longer for referral became particularly concerned about their child's poor weight gain.

Sixty one per cent (16 mothers) reported blaming themselves for their child's poor weight gain, feeling that they had not done sufficient to ensure adequate weight gain. They recalled feeling angry towards their child, as they had devoted much effort in attempting to increase their child's weight without success. After referral, 84\% (22 mothers) believed that the greatest benefit was being reassured that there was no underlying organic cause. Sixteen per cent (four mothers) remained worried that 'something had been missed'. Some mothers felt that being asked to attend for follow up appointments at the hospital undermined the previous reassurance given.

\section{MOTHERS ATTITUDES TO CHILD'S WEIGHT AND} SHAPE

Despite each child's weight being at the third centile or below, $58 \%$ ( 15 mothers) believed their child to be of normal weight or just slightly underweight. Thirty eight per cent (10 mothers) perceived their child's shape as normal, with a further $34 \%$ (nine mothers) stating that their child was only slightly thin.

Thirty eight per cent ( 10 mothers) described their child being a somewhat finicky eater, and a further $23 \%$ (six mothers) reported that their child was extremely finicky. A wide range of foods were reported as being refused, particularly foods that had a 'coarse' texture. As a result of their child's finicky eating, mothers described mealtimes being mostly tense, as they 'battled' over food intake with their child.

Fifty per cent (13 mothers) stated that they restricted their child's intake of 'sweet' foods such as sweets, chocolate, and biscuits; $30 \%$ (eight mothers) admitted to restricting other types of food (for example, fried foods, meat, nuts), as they considered them to be unhealthly and possibly fattening. After referral, 54\% (14 mothers) attempted to increase their child's food intake by having more frequent meals and increasing the quantity of food given.

\section{MANAGEMENT}

All families received a combination of dietary advice, together with feeding and psychological management, on an outpatient basis and a few cases required social services involvement. None were admitted to hospital for treatment.

The parents were encouraged to discuss in detail the difficulties they were having in feeding their child and how this made them feel. This provided an opportunity for staff to explore the parents own attitudes to food, shape, and weight and to examine further how the parent's attitudes influenced adversely the 
management of their child's feeding difficulties. Depending on the nature and severity of the problem, parents and their child were seen monthly and the duration of the intervention ranged from three months to two years.

Parents of the children of 'finicky' eaters found that clarification of their child's feeding difficulties, together with the support and advice regarding firm, consistent management of their child, led to an increase in energy intake and a general improvement in mealtime behaviour.

In five cases, assessment of the patient's energy intake from weekly recordings revealed that their intake was grossly inadequate. In four of these cases, psychosocial difficulties were evident, including marked parenting difficulties, relationship problems between parents, maternal depression and anxiety. In one of the five cases, both parents were vegans. They subsequently placed their child on a vegan diet, which proved nutritionally deficient. These five cases appeared to respond best to treatment.

All the children put on weight and, at discharge from the outpatient clinic, their mean centile was at the 5 th centile (range 3rd-25th centile), with their mean weight deficit for height being $11 \cdot 2 \%$ (range $3 \%-20 \%$ ), which was significantly improved compared with referral measures $(t=4 \cdot 35$, $\mathrm{p}<0.001)$.

\section{Discussion}

The main finding of this study is that, although mothers of children with non-organic failure to thrive were not suffering from clinical eating disorders, they did score significantly higher on the restraint subscale of the eating disorder examination. Another significant finding was that, despite their children having been referred to paediatricians for poor weight gain, half the mothers reported restricting moderately (that is, more than four days per week) their child's intake of sweet foods, and 30\% described restricting foods considered to be fattening or unhealthy. These findings are striking as one would expect that the mothers of children with non-organic failure to thrive would be attempting to increase their child's food intake rather than restrict it. These results could be explained as arising from the belief that sweet or fattening foods are unhealthy and therefore need to be restricted. Another possibility is that the high level of dietary restraint in the mother led her to restrict the child's food intake as well.

The findings of this study raise the question of whether a causal link exists between the index mothers' own dietary restraint and the poor growth of their child. Clearly, the relatively small sample size, the cross sectional nature of the study, and the lack of comparative data on the children in the comparison group, limits the conclusions that can be drawn. However, were further studies to implicate a causal role for maternal eating habits and attitudes in the genesis of non-organic failure to thrive, this would have important implications for management.

Given the study's findings, further research is indicated on the eating habits and attitudes of the mothers of children with non-organic failure to thrive. From a clinical perspective, assessment of parents' eating habits and attitudes would seem warranted when assessing such children. When abnormalities are found, management needs to address the parents' eating habits and attitudes.

Jacinta McCann was supported by a Wellcome Trust research registrar post, Alan Stein is a Wellcome Trust lecturer, and Christopher Fairburn, is a Wellcome Trust senior lecturer.

The community study from which the comparison data were drawn was funded by a programme grant from the Wellcome Trust. We are grateful to the families who participated in the study and to Dr Harvey Marcovitch who assisted in the recruitment of the sample.

1 Berwick DM, Levy JC, Kleinerman R. Failure to thrive: diagnostic yield or hospitalisation. Arch Dis Child 1982 57: $347-51$.

2 Hannaway PJ. Failure to thrive. A study of 100 infants and children. Clin Pediatr (Phila) 1970; 9: 96-9.

3 Patton RG, Gardner L. Growth failure in maternal deprivaion. Springfield, Illinios: Charles C Thomas, 1963.

4 Fischoff J, Whitten C, Pettit M. A psychiatric study of mothers of infants with growth failure secondary to maternal deprivation. $\mathcal{f}$ Pediatr 1971; 79: 209-15.

5 Homer C, Ludwig S. Categorisation of aetiology of failur to thrive. Am $\mathcal{F}$ Dis Child 1978; 132: 967-9.

6 Russell Davis D, Apley J, Fill G, Grimwaldi C. Diet and retarded growth. $B M F$ 1978; i: 539-42.

7 Whitten CF, Pettit MG, Fischoff J. Evidence that growth failure from maternal deprivation is secondary to undereating. $¥ A M A 1969 ; 209$ : 1675-82.

8 Skuse DH. Non-organic failure to thrive: a reappraisal. Arch Dis Child 1985; 60: 173-8.

9 Dagnelie PC, Staveren WA van, Vergote FJVRA, Burema J. Nutritional status of infants aged 4 to 18 months on macrobiotic diets and matched control infants: a population-based mixed-longitudinal study. Eur $f$ Clin Nut 1989; 43: 325-38

10 Dagnelie PC, Staveren WA van, Klaveren JD van, Burema J Do children on macrobiotic diets show catch-up growth? A population-based cross-sectional study in children aged 0-8 years. Eur f Clin Nutr 1988; 42: 1007-16.

11 Pugliese MT, Weyman-Daum M, Moses N, Lifshitz F. Parental health beliefs as a cause of non-organic failure to thrive. Pediatrics $1987 ; 80$ : $175-81$.

12 Van Weizel-Meijler G, Wit JM. The offspring of mothers with anorexia nervosa: a high-risk group for under with anorexia nervosa: a high-risk group for under
nutrition and stunting? Eur $f$ Pediatr 1989; 149: 130-5.

13 nutrition and stunting? Eur f Pediatr 1989; 149: 130-5. vosa. BMf 1989; 229: 777-8.

14 Lacey JH, Smith G. Bulimia nervosa: the impact of pregnancy on mother and baby. Brf Psychiatry 1987; 150 777-81.

15 Brinch $M$, Isager T, Tolstrup $K$. Anorexia nervosa and motherhood: reproduction pattern and motherin behaviour of 50 women. Acta Psychiatr Scand 1988; 77 611-7.

16 Tanner JM, Whitehouse RH, Takaishi M. Standards from birth to maturity for height, weight, height velocity, and weight velocity: British children 1965. Part I. Arch Dis Child 1966; 41: 454-71.

17 Tanner JM, Whitehouse RH, Takaishi M. Standards from birth to maturity for height, weight, height velocity, and weight velocity: British children, 1965. Part II. Arch Dis weight velocity: British

18 Cooper $Z$, Fairburn $C$. The eating disorder examination: a semi-structured interview for the assessment of the specific psychopathology of eating disorders. International fournal of Eating Disorders 1987; 6: 1-8. 